\title{
A AVALIAÇÃO ESCOLAR: UM INSTRUMENTO A FAVOR DO CONHECIMENTO E DA APRENDIZAGEM
}

\author{
Rita Virgínia dos Reis de Assis ${ }^{1}$ \\ Vilma Barbosa Santos ${ }^{2}$
}

\begin{abstract}
RESUMO
Este artigo tem como objetivo refletir o papel da avaliação da aprendizagem no ambiente escolar numa sociedade norteada pelos ideais capitalistas, apontando para a necessidade de mudança na prática avaliativa na perspectiva de que esta funcione como instrumento que favorece a aprendizagem, para a construção de conhecimentos significativos e para a formação de sujeitos críticos, capazes de contribuir para a superação das desigualdades sociais. Para alcançar este objetivo, recorremos a revisão de literatura envolvendo autores cujos estudos apresentam argumentos nesta perspectiva de que a avaliação torne-se uma ação reflexiva, mediadora na construção do conhecimento e na formação dos sujeitos. Concluiu-se que os modelos avaliativos têm passado por mudanças visando serem mais qualitativos e significativos no processo de aprendizagem, ressaltando a necessidade de atualização das práticas no cotidiano do ambiente escolar e do fortalecimento da autonomia dos sujeitos nele presentes.
\end{abstract}

Palavras - chave: Educação; Capitalismo; Práticas Educativas; Avaliação.

\section{ABSTRACT}

This article aims to reflect the role of learning assessment in the school environment in a society guided by capitalist ideals, pointing to the need for change in evaluative practice in the perspective that it works as an instrument that favors learning, for the construction of meaningful knowledge and for the formation of critical subjects, capable of contributing to the overcoming of social inequalities. To achieve this goal, we resorted to a literature review involving authors whose studies present arguments in this perspective that the evaluation becomes a reflexive action, mediating in the construction of knowledge and in the formation of the subjects. It was concluded that the evaluative models have undergone changes aiming to be more qualitative and significant in the learning process, emphasizing the need to update practices in the daily life of the school environment and to strengthen the autonomy of the subjects present in it.

Key Words: Education; Capitalism; Educational Practices; Evaluation

\section{INTRODUÇÃO}

Atuar como profissional da educação nos dias atuais requer um olhar permanente para as necessidades de ajustes ao exercício da profissão visando aperfeiçoar o processo de ensino e aprendizagem de modo a cumprir a sua finalidade de construir conhecimentos significativos na formação de cidadãos

\footnotetext{
${ }^{1}$ Graduada em geografia pela UNIJORGE. Especialista em Psicopedagogia pela FACEBA. Docente Pedagógica de Ensino Fundamental I e II na Prefeitura Municipal de São Francisco do Conde-BA. . Mestra em Ciências da Educação pela Faculdade Interamericana de Ciências Sociais - FICS. Email: virginia45netto@gmail.com

2 Graduada em Pedagogia pela FEBA - Faculdade de Educação da Bahia; Bacharel em Interdisciplinar em Humanidades pela UFBA - Universidade Federal da Bahia. Especialista em Avaliação da Aprendizagem pela UNEB - Universidade do Estado da Bahia. Mestra em Ciências da Educação pela Faculdade Interamericana de Ciências Sociais - FICS. Email: ric.vilma@gmail.com.
} 
críticos, que vão promover a transformação social, contribuindo assim para o desenvolvimento da sociedade e dos sujeitos de forma significativa e eficiente.

Ao longo da vida todos passam por um momento ou processo de avaliação, avaliando e ou sendo avaliado. Na escola este é um procedimento sempre presente norteando as atividades e seus resultando são parâmetros para ações futuras. Ao longo dos tempos tornou-se a pedra de toque do processo de ensino e aprendizagem, exigindo continuamente reflexão e tomadas de decisão por parte dos professores e profissionais da educação desde a concepção de avaliação da aprendizagem até os modelos e formas de aplicação na tentativa de ajustar modelos, instrumentos e práticas avaliativas à realidade e exigências do contexto educacional.

No entanto, as transformações por que passa a sociedade e os seus sistemas, dentre eles o educacional, suscita mudanças nas práticas desenvolvidas no ambiente escolar visando contribuir para o desenvolvimento dos sujeitos de forma significativa e eficaz. A prática da avaliação passa por esse processo buscando diversificar modelos e práticas avaliativas de forma que proporcione a construção de conhecimentos e o desenvolvimento do educando.

A avaliação da aprendizagem nesse sentido deverá ser um instrumento que contribui para o fortalecimento do papel da escola enquanto instituição que se destina a preparar crianças, jovens e adultos para o futuro e do processo de ensino e aprendizagem na construção de conhecimentos que vão formar sujeitos dinâmicos no processo de construção e transformação de saberes.

A avaliação é um processo abrangente, que implica uma reflexão de toda a prática educacional, na busca de avanços para superar as dificuldades que dificultam a aprendizagem dos alunos. É um processo importante na democratização e melhoria da qualidade do ensino contribuindo para a transformação da sociedade na qual estamos inseridos, formando sujeitos críticos e capazes de avaliar-se a partir da própria aprendizagem. Pode-se considerar que:

A avaliação gerou até uma verdadeira lógica do absurdo e da qual podem ser destacadas algumas ideias que tentam explicar a lógica da prática avaliativa nas escolas, tais como de valorizar demasiadamente a nota, de criar um clima de tensão no momento de sua aplicação, dentre outras (VASCONCELOS, 1995, p.15).

A necessidade de (re) pensar e (re) construir o processo de avaliação da aprendizagem escolar na sociedade contemporânea pressupõe uma transformação 
já na compreensão de que este deve ser um movimento dialético que envolve ação - reflexão - ação de todos os envolvidos, onde alunos e professores são sujeitos ativos e a escola um espaço de produção e construção de conhecimento dinâmico e reflexivo, e que o seu resultado, que é a aprendizagem, vale muito mais que uma nota, e uma vez que avaliar tem sentido significativo se for utilizado como diagnóstico num projeto de mudanças.

Promover mudanças na prática avaliativa escolar implica em questionar a concepção de educação, sua função social, organização e normas, o papel de professores, significação dos conteúdos, funcionalidade de técnicas e práticas na promoção da construção do saber, e até de como esse saber construído é significativo para a formação do aluno enquanto ser social crítico e transformador da sociedade.

\section{BREVE CONTEXTO HISTÓRICO DA AVALIAÇÃO}

Uma análise da história da avaliação permite compreender que desde sua origem o propósito da avaliação foi o de classificar. A avaliação teve inicio na escola moderna com a prática de provas e exames, que pretendiam mediar e avaliar a experiência com objetivos predefinidos com a função de classificar. No século XVI a pedagogia jesuítica utilizava o ritual das provas e exames em sessões solenes com formação de bancas examinadoras e comunicação dos resultados (LUCKESI, 2005).

No século XVII, a pedagogia comeniana utiliza os exames como meio de estimular os estudantes, a nota nesse contexto é o mais importante, o percurso do processo de ensino e aprendizagem não importava.

O período de 1930 a 1945 ficou conhecido como o período tyleriano da avaliação da aprendizagem, proposto por Ralph Tyler Integrado ao modelo de currículo que possui um caráter de controle de planejamento correspondente ao modelo do processo de produção industrial que ficou conhecido como avaliação por objetivos, ou seja, o processo avaliativo resumia-se à verificação das mudanças ocorridas a partir dos objetivos previamente definidos pelo professor.

O termo avaliação passou a ser utilizado na década de 30 , e apesar de muitos educadores acreditarem que a avaliação poderia e deveria subsidiar uma maneira mais eficiente de fazer o processo de ensino, a prática avaliativa norteada pela aplicação de provas e exames continuou sendo a vigente nas escolas (LUCKESI, 2005). 
Nos dias atuais, nas escolas brasileiras, em todos os níveis de ensino, pratica-se exames escolares no lugar de avaliação da aprendizagem, o que denomina-se de "Pedagogia do Exame". Vale destacar que maior problema que afeta os professores em geral é a distancia entre a teoria e a prática. A avaliação, portanto, acaba desempenhando na prática, um papel mais político que pedagógico, não é usada como recurso metodológico de reorientação do processo ensino e aprendizagem, mas sim como instrumento de poder, de controle, tanto por parte do sistema social, da escola, pelo professor, quanto pelos próprios pais. (VASCONCELOS, 2006)

Ao longo dos últimos anos, o modelo de avaliação da aprendizagem passou por diversas mudanças na tentativa de substituir os primeiros modelos e avançar numa perspectiva de avaliação qualitativa da aprendizagem onde aluno e professor têm uma postura mais ativa no processo e outros fatores presentes no contexto do processo são considerados. Dessa forma, o aspecto predominantemente quantitativo não é o mais importante.

\section{A FUNÇÃO DA ESCOLA}

Historicamente em nossa sociedade a escola é a instituição considerada como a ideal para preparar crianças e jovens para a vida, para o mercado de trabalho, enfim para o desenvolvimento do sujeito enquanto pessoa e profissional para ocupar seu espaço e papel no contexto social e do trabalho.

Numa perspectiva redentora, a escola é considerada uma alavanca que prepara jovens e crianças para o futuro, relacionando de maneira muito comum a educação e o nível de escolaridade com o sucesso que a pessoa poderá alcançar ao longo da vida (LUCKESI,1994). A escola nessa perspectiva é vista como um meio de melhoria de vida e mobilidade no contexto social.

Em se tratando da função, compreende que não é função da escola formar profissionais ou mão de obra para o mercado de trabalho, esta seria uma função do próprio mercado. A função da escola é ensinar/transmitir os conteúdos construídos historicamente pela sociedade nutrindo os alunos de conhecimentos diversos, que contribuam para que estes percebam as injustiças do sistema e assim possam trabalhar para a superação da injustiça social (SAVIANI, 2002). A escola assim estaria trabalhando em prol da formação do sujeito, possivelmente melhores, críticos e mais humanizados. 
A escola deve estar preparada para formar o sujeito para o mercado de trabalho e para a vida, voltar-se principalmente para a formação de homens críticos capazes de participar ativamente da transformação da sociedade, não se tratando de formar mão de obra para o "mercado de trabalho", mas formar cidadão/trabalhador capaz de sobreviver num sistema de organização capitalista. Vale ressaltar que:

A posse dos conhecimentos que permitem a compreensão e a inserção no mundo do trabalho é direito dos trabalhadores, por ser estratégica para sua sobrevivência, mas principalmente para a construção de seu objetivo político enquanto classe comprometida com a transformação das relações de dominação entre capital e trabalho (KUENZER, 2003, p.44).

Inserida numa sociedade norteada pelas ideias capitalistas em seus aspectos sociais, econômicos e políticos, a escola reproduz no desenvolvimento de suas práticas diversas lógicas do capitalismo a exemplo da classificação dos alunos com melhores rendimentos a partir da avaliação da aprendizagem e do reconhecimento midiático daqueles que conseguem as melhores classificações em concursos vestibulares, assim como quando relaciona maior e melhor escolaridade com o emprego e renda melhores.

\section{A PRÁTICA PEDAGÓGICA E A AVALIAÇÃO DA APRENDIZAGEM}

O trabalho pedagógico enquanto conjunto de práticas sociais intencionais e sistematizadas, por vezes fragmentado, reflete o disciplinamento do mundo do trabalho capitalista onde prevalece a divisão social e técnica do trabalho que tem como base organizacional os princípios do taylorismo e do fordismo. Tais princípios são fundamentados no rompimento entre pensamento e ação, considerando prioritariamente a ação pela ação independente do pensamento e da reflexão. Podese afirma que:

\footnotetext{
O trabalho pedagógico, enquanto conjunto das práticas sociais intencionais e sistematizadas de formação humana que ocorrem nas relações produtivas e sociais, embora expresse, em parte, a concepção de trabalho em geral, porquanto se constitui em uma das formas de construção material da existência através da reprodução do conhecimento, não deixa de se constituir no capitalismo, em uma de suas formas de expressão (KUENZER, 2002, p.82).
}

Instala-se uma divisão entre a teoria e a pratica, ou seja, entre as atividades intelectuais e a as atividades práticas no trabalho escolar. A escola então agrega a sua função a necessidade de atender às expectativas da sociedade de que os estudantes, futuros profissionais, aprendam nela os meios necessários à sua 
inserção no mercado de trabalho, a sua melhoria da qualidade de vida, concretizando o disciplinamento do mundo do trabalho capitalista no contexto escolar.

A teoria social de Marx tem como referencial teórico a categoria trabalho. trabalho é o elemento que difere os homens dos animais, especificamente pela capacidade de organizar a ação e prever os resultados da ação (MARX, 1987).

Existe uma relação entre a educação e o trabalho como necessária e fundamental, pois ambos fazem parte da natureza do homem, sendo assim a educação é o processo de trabalho que produz e reproduz a existência humana garantindo a subsistência.

O processo de trabalho garante a subsistência material pela produção de bens materiais, mas, para que este se torne efetivo, o homem precisa antecipar em forma de idéias os objetivos da ação, o que para ele se constitui em outra categoria de trabalho na qual a educação se encaixa, pois:

Tais aspectos [ciência, ética e arte], na medida em que são objetos de preocupação explícita e direta abrem a perspectiva de uma outra categoria de produção que pode ser traduzida pela rubrica "trabalho não material". Trata-se aqui da produção de idéias, conceitos, valores, símbolos, hábitos, atitudes, habilidades. Numa palavra, trata-se da produção do saber, seja do saber sobre a natureza, seja do saber sobre a cultura, isto é, o conjunto da produção humana. Obviamente, a educação situa-se nessa categoria do trabalho não-material (SAVIANI, 2005,12).

Nesta perspectiva, a educação e suas práticas e o conhecimento construído no espaço escolar deverão contribuir para o pleno desenvolvimento do sujeito, visto que este conhecimento não é mercadoria, nem deve ser encarado como tal, mas deve constituir-se no e como meio de um processo construção, formação e transformação humana e social.

A avaliação da aprendizagem enquanto prática escolar se constitui ao longo dos tempos numa das formas que fragmenta a teoria da prática no contexto escolar, isto porque em termos teóricos a avaliação está relacionada ao processo de ensino e de aprendizagem. Em relação à Avaliação da aprendizagem a favor da democratização do ensino destaca-se que:

A avaliação no contexto escolar, muitas vezes se resume na ação de atribuir notas e conceitos, rotulando o aluno por meio de um atributo quantitativo que não se concretiza como uma ação reflexiva, com indicativos importantes para que o professo redimensione sua prática pedagógica, repensando e replanejando sua atuação didática, visando aperfeiçoá-la (HANSEM, 2016, p.2)) 
Na prática, a avaliação se desvincula deste processo quando se constitui em elemento que favorece o fracasso escolar e a estigmatização social ao valorizar aspectos que classificam e não consideram o conhecimento construído como um todo, envolvendo o sujeito, o contexto e diversos fatores que estão presentes no processo de ensino e de aprendizagem.

\section{A AVALIAÇÃO ESCOLAR}

As discussões e políticas públicas refletem a tentativa de teóricos e educadores de reverter a ideia inicialmente autoritária e excludente do papel da avaliação neste processo. Faz-se necessário afirmar que

É necessário encaminhar a avaliação, a partir da efetiva relação professor e
aluno, em benefício da educação dando a todos oportunidades reais de
aprendizagem e contrapondo-se a exclusão escolar uma vez que “insistir
na reprovação e nas práticas tradicionais de avaliação, viajando na
contramão da evolução teórica em educação, como solução para problemas
que são políticos e administrativos é, no mínimo, cruel e antiético".
(HOFFMANN, 2005, p.60).

Nos dias atuais busca-se compreender o processo de avaliação como ponto norteador fundamental do processo de ensino e de aprendizagem A Lei de Diretrizes e Base da Educação nacional oㅜ 9394/96 denota que a avaliação significa apropriarse do saber, sugerindo que haja um novo olhar sobre a avaliação e uma mudança no processo de ensinar visando a aprendizagem. Sugere um acompanhamento individual, um diagnóstico do saber prévio do aluno, um planejamento a partir do nível de cognição para o reconhecimento de alcance dos objetivos traçados.

A legislação e as propostas curriculares vigentes reconhecem e valorizam a avaliação como parte do processo contínuo da aprendizagem e não como um momento estanque do processo de ensino e de aprendizagem, reiterando que a avaliação deve ser diagnóstica, contínua e formativa do desempenho do aluno.

A proposta da avaliação da aprendizagem na escola cidadã propõe uma ruptura com visões tradicionais, funcionalistas ou técnicos - mecanicistas que permeiam a educação e consequentemente as práticas pedagógicas decorrentes, assumindo uma posição que contemple sujeitos do ato educativo, pois: 
escolar, a avaliação se caracteriza como processual, contínua, participativa, diagnóstica e investigativa (ESTEBAN, 2001, p.132)

Para que a avaliação se torne efetivamente um instrumento de função diagnóstica e reorientadora do processo de aprendizagem, deverá ser como diz Luckesi (2005) como um "instrumento dialético" que reconhece os caminhos percorridos e identifica os caminhos a serem percorridos. A avaliação nessa perspectiva direciona o objeto a ser apreendido, o saber, numa caminhada dinâmica.

A avaliação da aprendizagem deve ser compreendida como um processo amplo e dinâmico que não se resume a um momento, as vezes único, do processo pedagógico, mas que deve ser um procedimento processual e continuo com permanente ação diagnóstica, com o objetivo de identificar o nível de desempenho do aluno e a partir dela tomar as decisões necessárias e ativa.

\section{CONSIDERAÇÕES FINAIS}

A necessidade de (re)pensar e (re)construir o processo de avaliação da aprendizagem escolar na sociedade contemporânea pressupõe uma transformação já na compreensão de que este deve ser um movimento dialético que envolve ação - reflexão - ação de todos os envolvidos, onde alunos e professores são sujeitos ativos e a escola um espaço de produção e construção de conhecimento dinâmico e reflexivo, e que o seu resultado, que é a aprendizagem, vale muito mais que uma nota, e uma vez que avaliar tem sentido significativo se for utilizado como diagnóstico num projeto de mudanças.

Nesta perspectiva, faz-se necessário modificar as práticas cotidianas na escola visando uma atuação inovadora que proporcione superação da segregação e da exclusão características do pensamento capitalista, e fortaleça a autonomia de alunos e professores de forma que favoreça a igualdade de oportunidades, de maneira contextualizada e integradora, tornando-se um espaço de conquista da cultura e da ciência como instrumentos na luta pelas desigualdades.

Quando se compreende que a escola é a local mais adequado para se ensinar, construir e vivenciar a democracia com suas características de igualdade e justiça acredita-se que as práticas desenvolvidas no ambiente escolar também o devam ser. Assim a avaliação da aprendizagem escolar não deverá centrar-se no caráter classificatório de aprovação ou reprovação, que é em si mesmo uma forma 
de exclusão, mas deve centrar-se no caráter construtivo e formativo do conhecimento e da aprendizagem.

A educação nesse sentido tem sua finalidade na formação integral do sujeito mediada pela construção de conhecimentos que proporcionarão uma aprendizagem significativa não somente para a utilização no mercado de trabalho com ideias mais humanizadas para transformar o contexto social e político, mas também para o exercício de uma vida com criticidade e cidadania.

\section{REFERÊNCIAS:}

ESTEBAN, M. T. Avaliação: uma prática em busca de novos sentidos. 3ed. Rio de Janeiro: DP\&A, 2001.

HANSEM, E. C. Avaliação da aprendizagem a favor da democratização do ensino. 2016.

HOFFMANN, J. Avaliação: mito e desafio: uma perspectiva construtivista. Porto Alegre: Mediação, 35ed, 2005.

KUENZER, A. Z .Trabalho pedagógico: da fragmentação à unitariedade possível. In: AGUIAR, Márcia Ângela da Silva; FERREIRA, Naura Syria Carapeto (Orgs.). Para onde vão a orientação e a supervisão educacional? Campinas: Papirus, 2002.

KUENZER, A. Z. As mudanças no mundo do trabalho e a educação: novos desafios para a gestão. In. FERREIRA, Naura Syria Carapeto et. al. Gestão Democrática da Educação: atuais tendências, novos desafios. 4. ed. São Paulo: Cortez, 2003.

LUCKESI, C. C Avaliação da aprendizagem na escola: reelaborando conceitos, recriando a prática. Salvador. Malabares Comunicação e Eventos, 2005. Filosofia da Educação. São Paulo: Cortez, 1994.

MARX, K. Trabalho assalariado e capital. 4ed., S. P., Global Editora,1987.

SAVIANI, D. O choque teórico da politécnica. Trabalho, Educação e Saúde, v. 1, n. 1, mar. 2002

SAVIANI, D. Pedagogia histórico-crítica: primeiras aproximações. 9ed., Campinas, Autores Associados, 2005.

VASCONCELOS, C. Avaliação: concepção dialética libertadora do processo de avaliação escolar. 15. Ed. São Paulo: Libertad, 2005.

VASCONCELOS, C. Avaliação: Concepção Dialética - libertadora do processo de avaliação escolar. 16 ed. São Paulo; Libertad, 2006. 